\title{
Relationships between Linear Sprint, Lower-Body Power Output and Change of Direction Performance in Elite Soccer Players
}

\author{
Monika Papla, Michal Krzysztofik*®D, Grzegorz Wojdala ${ }^{\circledR}$, Robert Roczniok®, Marcin Oslizlo \\ and Artur Golas \\ Institute of Sport Sciences, The Jerzy Kukuczka Academy of Physical Education in Katowice, 40-065 Katowice, \\ Mikolowska 72a, Poland; m.papla15@gmail.com (M.P.); wojdala.grzegorz@gmail.com (G.W.); \\ r.roczniok@awf.katowice.pl (R.R.); m.oslizlo@awf.katowice.pl (M.O.); a.golas@awf.katowice.pl (A.G.) \\ * Correspondence: m.krzysztofik@awf.katowice.pl
}

Received: 17 July 2020; Accepted: 21 August 2020; Published: 22 August 2020

\begin{abstract}
The aim of this study was to investigate the relationship between linear sprint, power output obtained during a squat and change of direction (COD) performance. Fifteen elite soccer players participated in this study (age $=21.7 \pm 0.72$ years, body mass $=74.9 \pm 9.11 \mathrm{~kg}$, body height $=180.4 \pm 7 \mathrm{~cm}$, training experience $=9 \pm 1.5$ years). To examine these correlations a following battery of tests were carried out: 20-m linear sprint, one-repetition maximum (1RM) squat strength, peak power output obtained during a squat at 50\% 1RM and time obtained in two 20-m COD tests with different angles of direction change $\left(90^{\circ}\right.$ and $\left.135^{\circ}\right)$. In addition, $\mathrm{COD}$ deficits $\left(90^{\circ}-\mathrm{COD}_{\mathrm{DEF}}\right.$ and $\left.135^{\circ}-\mathrm{COD}_{\mathrm{DEF}}\right)$ for both COD tests were calculated. The Spearman's rank order correlation showed a nearly perfect statistical relationship between the $90^{\circ}$-COD and the $90^{\circ}-\mathrm{COD}_{\mathrm{DEF}}(\mathrm{r}=0.9 ; p<0.001)$. In the case of $90^{\circ}-\mathrm{COD}_{\mathrm{DEF}}$, there was a large statistical relationship with $135^{\circ}-\mathrm{COD}_{\mathrm{DEF}}(\mathrm{r}=0.59 ; p=0.021)$. Moreover, there was a nearly perfect statistical relationship between $135^{\circ}-\mathrm{COD}$ and $135^{\circ}-\mathrm{COD}_{\mathrm{DEF}}(\mathrm{r}=0.91 ; p<0.001)$. The statistically insignificant $(p>0.05)$ relationship between $20-\mathrm{m}$ linear sprint time, power output obtained during a squat at 50\% 1RM, 1RM squat strength level and both COD test, as well as both COD deficits were found. Results of the present study showed that 20-m linear sprinting speed, 1RM squat strength, power output obtained during squat at 50\% $1 \mathrm{RM}$ and COD ability at $90^{\circ}$ and $135^{\circ}$ angles, are separate physical qualities. Moreover, it seems that COD deficit provides a more isolated measure of COD ability than the COD tests alone and does not must be limited to a specific angle, but provides knowledge about the COD ability in a range of other angles, at least concerning $90^{\circ}$ and $135^{\circ}$ COD angles.
\end{abstract}

Keywords: agility; COD deficit; squat power; team sports; speed

\section{Introduction}

Most team sports require players to jump, sprint and change direction very frequently; such sports include American football, rugby and soccer [1,2]. During a soccer match, players make over 700 turns with different changes of direction (COD) [3], as well as numerous jumps and sprints [4]. During a COD, athletes' ability to accelerate, decelerate and reaccelerate in a new direction requires a rapid application of force. The acceleration phase in COD and linear sprint involves similar technical factors, so improving acceleration capability may be beneficial in terms of accelerating quickly after successive COD maneuvers and transition between them. Hence, it can be assumed that linear speed and lower-body power output may affect COD performance. Given that, many researchers examined the relationship between the performance of the above mentioned high-intensity actions 
and reached varying degrees of association, further studies seem justified [5-10]. Previous studies indicate a statistically significant large to very large relationships between linear sprints and different COD sprints $\left(45^{\circ}, 60^{\circ}, 90^{\circ}\right.$ and $135^{\circ}$ changes of direction) at various distances [7-9,11]. Additionally, Suarez-Arrones et al. [10] showed a statistically significant moderate and large relationship between $10-\mathrm{m}$ linear sprint and equal distance different COD sprints $\left(90^{\circ}\right.$ and $180^{\circ}$; respectively). At the same time, Loturco et al. [9] revealed no statistically significant relationship between $100^{\circ} \mathrm{COD}$ test and linear sprints at $5 \mathrm{~m}$, as well as on $10 \mathrm{~m}$.

Profiling of COD performance is difficult due to a variety of tests used in research. Certain COD tests differing in length, angle and a number of direction changes. Therefore, they may have different physical and mechanical requirements. In regards to the COD angles, as suggested by Falch et al. [12] and Bourgeuis et al. [13] angels below $90^{\circ}$ are more velocity-oriented in contrast to the angles above $90^{\circ}$, which are more force-oriented. Consequently, it can be assumed that COD performance with the angles below $90^{\circ}$ and that which exceeding $90^{\circ}$ should be measured and trained separately. Regarding the number of direction change, a majority of COD tests consists of two or more turns [14], however in case of soccer players, it is rare to change direction more than three times during matches [15]. With respect to the fatigue caused by hundreds of COD during a soccer match, the use of COD tests with several or repeated COD tests seems warranted when the COD ability is assessed among soccer players.

The solution that can shed new light on the assessment of COD ability, is a measurement of COD deficit. However, to date little attention has been given to the relationship between COD deficit and the performance of the high-intensity actions and COD tests $[2,10,15,16]$. The COD deficit is an additional time that athletes need, to complete running with a COD in comparison to straight-line sprint at the same distance (e.g., athlete's 20-m sprint time is subtracted from the 20-m COD time). This difference in time allows to better isolate and identify an athlete's ability to change direction [2]. The lower the value, the greater the COD ability. A study by Nimphius et al. [2] showed a statistically significant positive relationship between COD deficit (measured as the difference between 10-m sprint time and $180^{\circ} \mathrm{COD}$ test) and COD test (505), but not with 10- and 30-m sprint time in male cricketers. In contrast, Loturco et al. [15] did not find a statistically significant relationship between COD deficit (measured as the difference between 20-m linear fly sprint and $100^{\circ} \mathrm{COD}$ test) and $100^{\circ} \mathrm{COD}$ test. However, the authors indicated a statistically significant positive moderate relationship between COD deficit and relative mean propulsive power obtained in the half-squat and sprint velocity at five meters. Furthermore, a large and nearly perfect relationship was found between 10- and 20-m linear flying sprint and COD deficit among elite soccer players. Moreover, Loturco and colleagues [15] found statistically significant positive large and nearly perfect relationship with 10-m and 20-m linear flying sprint, respectively. In reference to the Nimphius et al. [2], the COD deficit may be specific to the angle and, as shown by the results of previous studies, may also for the length of run, discipline and the type of start (standing vs. flying). Therefore, in order to increase the versatility of this measure, there is a need for research which compare the COD tests and COD deficits with different direction change and running length in the same group of athletes.

Therefore, the aims of this study were to examine the relationships between a $20-\mathrm{m}$ linear sprint, $1 \mathrm{RM}$ squat strength, peak power output obtained during a squat at $50 \% 1 \mathrm{RM}, 90^{\circ}$ and $135^{\circ} \mathrm{COD}$ tests. A second aim of this study was to analyze the possible relationships between the COD deficits (using $90^{\circ}$ and $135^{\circ} \mathrm{COD}$ time and $20-\mathrm{m}$ sprint time) with all considered tests. It was hypothesized that significant relationships between all measured variables will exist. The second hypothesis was that peak power output obtained in the squat and 20-m linear sprint would be positively correlated with the COD deficit and the magnitude of correlation will depend on the angle of change. 


\section{Materials and Methods}

\subsection{Experimental Design}

To examine the relationship between linear sprint, lower-body maximum strength and power output as well as COD performance, the following tests were carried out: 20-m linear sprint, one-repetition maximum (1RM) squat strength, peak power output obtained during a squat at $50 \% 1 \mathrm{RM}$ and two separate $20-\mathrm{m} \mathrm{COD} \mathrm{sprints,} \mathrm{first} \mathrm{with} \mathrm{a} 90^{\circ}$ and the second with a $135^{\circ}$ direction change angles. To assess a more isolated measure of the COD performance, the COD deficits for both conducted tests were calculated. Measurements were conducted on two different sessions, $72 \mathrm{~h}$ apart. Linear and COD sprints were performed during the first session, and $72 \mathrm{~h}$ later the lower-body power output was assessed.

\subsection{Study Participants}

Fifteen elite male soccer players from a professional team participated in the study (Second Polish League) (age $=21.7 \pm 0.72$ years, body mass $=74.9 \pm 9.11 \mathrm{~kg}$, body height $=180.4 \pm 7 \mathrm{~cm}$, training experience $=9 \pm 1.5$ years, $1 \mathrm{RM}$ squat $=200 \pm 8.7 \mathrm{~kg}$ ). The athletes were all full-time professionals who trained daily. All athletes had valid medical examinations and showed no contraindications to participate in physical fitness tests. The experimental sessions took place at the beginning of the pre-season. The athletes were instructed to maintain their normal dietary habits over the course of the study and not to use any supplements or stimulants for the duration of the experiment. Moreover, they were informed verbally and in writing about the experimental protocol, the possible risks and benefits of the study and the possibility to withdraw at any stage of the experiment. All players gave their written consent for participation. The study protocol was approved by the Bioethics Committee for Scientific Research (10/2018), at the Academy of Physical Education in Katowice, Poland and performed according to the ethical standards of the Declaration of Helsinki, 2013.

\subsection{Testing Procedures}

One week prior to starting the experimental sessions, all athletes were familiarized with the testing procedures and 1RM test for the Keiser Squat exercise. The experimental sessions were carried out at the same time of the day (between 9:00 and 11:00 a.m.) $72 \mathrm{~h}$ apart. Both sessions were preceded by the same warm-up protocol, which included $5 \mathrm{~min}$ of jogging, dynamic stretching, a single attempt of a 20-m linear sprint and two different COD sprints $\left(90^{\circ}\right.$ and $\left.135^{\circ}\right)$ at submaximal intensity and 2 sets of body-weight squats. During the first experimental session, the athletes performed a $20-\mathrm{m}$ linear sprint and 20-m COD sprints with two different turn angles $\left(90^{\circ}\right.$ and $\left.135^{\circ}\right)$. All sprint tests were performed on an indoor court. The running times were recorded by two pairs of dual-beam Witty Gate photocells (Microgate, Bolzano, Italy) with the measuring precision of $0.01 \mathrm{~s}$. The intraclass correlation coefficient for the test-retest reliability in times of linear sprinting and COD tests measured by used photocells ranged from 0.96 to 0.99 . In the second experimental session peak power output obtained during a squat exercise at 50\% 1RM was assessed using the Keiser Air 300 Squat pneumatic machine (Keiser Corporation, Fresno, CA, USA). This value of the external load was chosen because it is the lower value of the range that was indicated as optimal for obtaining the highest values of peak power outputs during a squat exercise [17]. The Keiser pneumatic resistance system utilizes air-pressurized resistance to maximize safety and allows for precision loading within one kilogram. The intraclass correlation coefficient for the test-retest reliability in the peak power output during a squat exercise measured by Keiser Air 300 Squat pneumatic machine was 0.97.

\subsubsection{One-Repetition Maximum Test}

One week before the first experimental session the 1RM squat exercise test was performed on the Keiser Squat air pneumatic machine. After a standardized warm-up, the athletes performed 10, 6, 4 and 
3 repetitions, starting at a load of $20 \mathrm{~kg}$ and progressing to $60-80 \%$ of their estimated 1RM. The first testing load was set to an estimated $90 \% 1 \mathrm{RM}$ and was increased by $5-10 \mathrm{~kg}$ for each subsequent attempt until the athlete was unable to perform a proper lift with a correct technique. The 1RM test result was determined within 5 attempts, with 5 min of rest in between attempts. All testing was performed with a constant tempo of movement $[18,19]$. The strength coaches were present throughout the procedure of 1RM testing. The athletes started from an upright position, with the knees and hips fully extended, the stance approximately shoulder-width apart with both feet positioned flat on the floor in parallel or externally rotated to a maximum of $15^{\circ}$ [20], hands were placed on the hand grips, and this setting was carefully replicated on every lift. From this position, they were required to descend until contact with the bench (without losing muscle tension) and then perform the concentric phase of the movement in an explosive manner. The height of the bench allowed each athlete to descend with the hips below the knee line to keep constant squat depth. No weight-lifting belts, shoes or other supportive garments were permitted.

\subsubsection{Linear Sprint Test}

Following the warm-up, all athletes performed 2 maximal 20-m linear sprints, interspersed with $5 \mathrm{~min}$ rest intervals. The athletes started with the front foot placed $0.5 \mathrm{~m}$ behind the first timing gate, to prevent any early triggering of the start gate. The athletes started when ready to eliminate the reaction time effect. The fastest time from both attempts was retained for further analysis.

\subsubsection{Change of Direction Tests}

Following the 20-m linear sprint test, the participants were provided with a 5 min rest interval before completing the COD tests. The two COD tests consisted of four 5-m sections marked with cones set at $90^{\circ}\left(90^{\circ}-\mathrm{COD}\right)$ and $135^{\circ}\left(135^{\circ}-\mathrm{COD}\right)$, requiring the athletes to decelerate and accelerate as fast as possible around each cone (Figures 1 and 2). The players executed two attempts of each COD test with 5 min rest intervals in between attempts and tests. The fastest time from each COD test was retained for further analysis.

\subsubsection{Change of Direction Deficits}

To provide a measure of each athletes' COD ability, an adapted COD deficit calculation was used. The COD deficit for both angles $\left(90^{\circ}-\mathrm{COD}_{\mathrm{DEF}}\right.$ and $\left.135^{\circ}-\mathrm{COD}_{\mathrm{DEF}}\right)$ was calculated as follows: 20 -m linear sprint time $-90^{\circ}$-COD for $90^{\circ}$ - $\mathrm{COD}_{\mathrm{DEF}}$ and 20 -m linear sprint time $-135^{\circ}$-COD for $135^{\circ}-\mathrm{COD}_{\mathrm{DEF}}$.

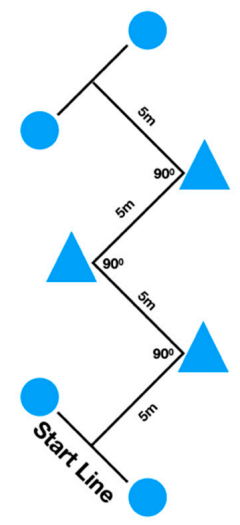

Figure 1. Schematic presentation of the $90^{\circ}$ change of direction test. Circles represent the positions of the photocells.

\subsubsection{Lower-Body Power Output}

Following the warm-up, a lower-body power output test was assessed using the squat exercise performed on the Keiser Squat air pneumatic machine at 50\% 1RM. The strength coaches were present 
throughout the test to ensure safety and to carefully replicate the setting on each lift. All athletes were instructed to perform the concentric phase of the movement as fast as possible. As during the 1RM test, no weight-lifting supportive garments were permitted. The players executed two attempts of lower-body power output with 5 min rest intervals in between. The best peak power output was considered for further analysis.

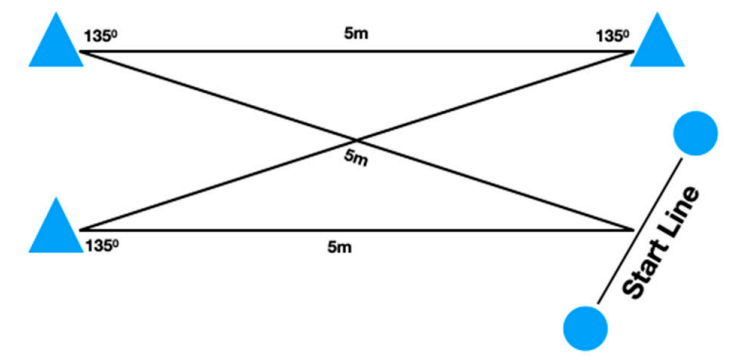

Figure 2. Schematic presentation of the $135^{\circ}$ change of direction test. Circles represent the positions of the photocells.

\subsection{Statistical Analysis}

All statistical analyses were performed using Statistica 9.1 (Hillview, Palo Alto, CA, USA). The physical tests of this study were: 20-m linear sprint, 1RM squat strength, peak power output in squat, $90^{\circ}$ and $135^{\circ}-\mathrm{COD}$ tests and $90^{\circ}$ and $135^{\circ}-\mathrm{CODD}_{\mathrm{DEF}}$. Data are presented as means and standard deviations (SD) with 95\% confidence intervals. The normality of the data were examined by the Shapiro-Wilk test. Due to the lack of normal distribution of the studied variables (linear sprint and $\left.135^{\circ}-\mathrm{COD}\right)$, the Spearman's rank order correlation was used to determine the relationship between all conducted tests. Correlations were evaluated as follows: trivial (0.0-0.09), small (0.10-0.29), moderate (0.30-0.49), large (0.50-0.69), very large (0.70-0.89), nearly perfect (0.90-0.99) and perfect (1.0) [21]. The significance level for the correlation analysis was set as $p<0.05$.

\section{Results}

Descriptive data for all the tests is shown in Table 1, while the Spearman's rank order correlations between all measured variables are presented in Table 2. There were no statistically significant relationships between peak power output obtained during squat at 50\% 1RM and all of the other measured variables. Further, there were no statistically significant relationships between squat 1RM and all of the other measured variables. Similarly, no statistically significant relationships between linear sprint and all of the other measured variables were found. In regards to the $90^{\circ}-\mathrm{COD}$ there was a nearly perfect statistically significant relationship with $90^{\circ}-\mathrm{CODD}_{\mathrm{DEF}}(\mathrm{r}=0.9 ; p<0.001)$. In case of $90^{\circ}-\mathrm{COD}_{\mathrm{DEF}}$, there was a large statistically significant relationship with $135^{\circ}-\mathrm{COD}_{\mathrm{DEF}}(\mathrm{r}=0.59$; $p=0.021)$. Moreover, there was a nearly perfect statistically significant relationship between $135^{\circ}-\mathrm{COD}^{\circ}$ and $135^{\circ}-\mathrm{CODD}_{\mathrm{DEF}}(\mathrm{r}=0.91 ; p<0.001)$.

Table 1. Descriptive data for all measured tests.

\begin{tabular}{ccc}
\hline Test & Mean \pm SD & 95\% CI \\
\hline Squat 1RM $(\mathrm{kg})$ & $200 \pm 8.7$ & 192 to 208 \\
\hline Linear Sprint $(\mathrm{s})$ & $3.02 \pm 0.1$ & 2.97 to 3.08 \\
\hline $90^{\circ}-\mathrm{COD}(\mathrm{s})$ & $7.07 \pm 0.25$ & 6.93 to 7.2 \\
$135^{\circ}-\mathrm{COD}(\mathrm{s})$ & $7.25 \pm 0.28$ & 7.09 to 7.4 \\
\hline $90^{\circ}-\mathrm{COD}_{\mathrm{DEF}}(\mathrm{s})$ & $4.04 \pm 0.21$ & 3.93 to 4.16 \\
\hline $135^{\circ}-\mathrm{COD}_{\mathrm{DEF}}(\mathrm{s})$ & $4.22 \pm 0.24$ & 4.09 to 4.35 \\
\hline Power Output Squat $(\mathrm{W})$ & $1408 \pm 129$ & 1337 to 1480 \\
\hline
\end{tabular}

Mean \pm standard deviation (SD); CI-confidence intervals; 1RM-one-repetition maximum; COD—change of direction; $\mathrm{COD}_{\mathrm{DEF}}$ - change of direction deficit. 
Table 2. Spearman's rank order correlations between all measured variables.

\begin{tabular}{|c|c|c|c|c|c|c|c|c|}
\hline Test & & Linear Sprint & Power Output Squat & $90^{\circ}$-COD & $90^{\circ}-\mathrm{COD}_{\mathrm{DEF}}$ & $135^{\circ}-\mathrm{COD}$ & $135^{\circ}-\mathrm{COD}_{\mathrm{DEF}}$ & Squat 1RM \\
\hline Linear Sprint & $\mathrm{r}$ & 1 & & & & & & \\
\hline Power Output Squat & $\mathrm{r}$ & -0.30 & 1 & & & & & \\
\hline $90^{\circ}-\mathrm{COD}$ & $\mathrm{r}$ & 0.43 & 0.09 & 1 & & & & \\
\hline $90^{\circ}-\mathrm{COD}_{\mathrm{DEF}}$ & $\mathrm{r}$ & 0.15 & 0.07 & 0.90 ** & 1 & & & \\
\hline $135^{\circ}$-COD & $\mathrm{r}$ & 0.29 & -0.30 & 0.33 & 0.38 & 1 & & \\
\hline $135^{\circ}-\mathrm{COD}_{\mathrm{DEF}}$ & $\mathrm{r}$ & 0.05 & -0.27 & 0.42 & $0.59 *$ & $0.91^{* *}$ & 1 & \\
\hline Squat 1RM & $\mathrm{r}$ & -0.16 & -0.23 & -0.17 & -0.02 & -0.05 & -0.01 & 1 \\
\hline
\end{tabular}

\section{Discussion}

The main finding of this study was that 1RM squat strength, peak power output obtained during a squat at 50\% $1 \mathrm{RM}$ and the 20-m linear sprint was not significantly correlated with each other and with any of the measured COD tests. However, there was a nearly perfect statistical relationship between the $90^{\circ}-\mathrm{COD}$ and $90^{\circ}-\mathrm{COD}_{\mathrm{DEF}}$ as well as between $135^{\circ}-\mathrm{COD}$ and $135^{\circ}-\mathrm{COD}_{\mathrm{DEF}}$. Furthermore, there was a large statistical relationship between $90^{\circ}-\mathrm{COD}_{\mathrm{DEF}}$ and $135^{\circ}-\mathrm{COD}_{\mathrm{DEF}}$. The results indicated that 20-m linear sprinting speed, 1RM squat strength and power output obtained during squat at $50 \%$ $1 \mathrm{RM}$, as well as COD ability at $90^{\circ}$ and $135^{\circ}$ angles, are separate physical qualities. Moreover, it seems that the COD deficit does not must be limited to a specific angle but provides knowledge about the COD ability in a range of other angles, at least concerning $90^{\circ}$ and $135^{\circ} \mathrm{COD}$ angles. Additionally, these data suggests that the COD deficit provides a more isolated measure of COD ability than the COD tests alone due to the reduced effect of linear sprinting speed within a COD test among elite soccer players.

A wide range of studies has been conducted to determine the applicability of a given exercise that leads to enhancement of specific athletic performance [22-25]. However, various resistance exercises are significantly related to performance of selected physical fitness tests. The lack of a statistically significant relationship between, 1RM squat strength and peak power output obtained in the squat exercise at 50\% 1RM and 20-m linear sprint, as well as with COD performance may be explained by different mechanical demands of the hip and knee extensors executing these high-intensity actions. A study by Contreras et al. [24] found that 6-week hip thrust training could be more beneficial in improving 10- and 20-m linear sprint times compared with front squat training, which may be superior in vertical jump height enhancement. In addition, González-García et al. [25] revealed that strength improvement after 7-week hip thrust training showed greater improvements in 10- and 20-m sprint, as well as in COD test $\left(90^{\circ}\right)$ in comparison to back squat training [25]. It is possible that the hip thrust has a stronger transfer to sprint running, whereas the squat has more influence on vertical jump performance [24]. Furthermore, a lack of relationship between 20-m linear sprint time and peak power output obtained in the squat at 50\% 1RM may be related to the used external load and measured variable. In the current study, the assessment of correlations is based only on a single value of external load ( $50 \% 1 \mathrm{RM} ; 100 \pm 4.35 \mathrm{~kg}$ ) and on peak power output. In turn, a study by López-Segovia et al. [26] showed significant positive correlations with 10-, 20- and 30-m linear sprint time with mean power output obtained in a full squat, but not with peak power output among soccer players. That relationship was found only at $70 \mathrm{~kg}$ which was close to the body mass of participants $(93 \%)$, but not at lower loads (from 20 to $60 \mathrm{~kg}$ with $10 \mathrm{~kg}$ increments). While in the present study, the external load used during the squat significantly exceeded the body mass of participants ( 133\%). These findings partially confirm the suggestion of López-Segovia et al. [26] that certain levels of neuromuscular activation, assessed by mean power output generated at loads to body may be related with linear sprint performance. Thus, future studies should examine the relationship between hip thrust and squat exercises at a wide range of external loads versus linear sprint, as well as COD performance.

To the best of the authors' knowledge, a limited number of studies have analyzed the relationship between linear sprint and the COD deficit among soccer players $[15,27,28]$. Findings of the current 
study revealed that 20-m linear sprint time was not statistically significant related to both COD deficits, what is contradict to findings of Loturco et al. [15]. The authors showed a statistically significant nearly perfect positive relationship between $100^{\circ} \mathrm{COD}$ deficit and 20-m flying start linear sprint in team-sport athletes. Moreover, Loturco et al. [15] found a statistically significant large positive relationship between $100^{\circ} \mathrm{COD}$ deficit and 10-m flying start linear sprint. Unfortunately, Loturco and colleagues [16] did not assess whether these results would be similar in the case of a linear sprint from the standing start. At the same time, Loturco et al. [28] revealed differences in the COD deficit between elite soccer players versus handball, rugby and futsal players. The COD deficit was significantly higher in soccer players in comparison with the remaining disciplines, which could be explained by the nature of these sports. It is important to note, that most COD-runs occur with angles between 0 and $90^{\circ}$ (approximately $84 \%$ ), with the next most common range of $90-180^{\circ}$ (approximately $13 \%$ ) in soccer players [3]. Therefore, the use of angles greater than $90^{\circ}$ in COD tests should be considered with logical validity when the goal is to assess the relationships between high-intensity actions and COD performance among soccer players. However, angles greater than $90^{\circ}$ occur much less frequently in a match, this should not be ignored, and players must also be prepared for such maneuvers. Therefore, the assessment of the relationship between COD tests and COD deficits with different angles, also exceeding $90^{\circ}$, seems justified from the training practice point of view. In the current investigation, there was a nearly perfect statistical relationship between performances in the COD tests and COD deficits for the same angles $\left(90^{\circ}-\mathrm{COD}\right.$ and $90^{\circ}-\mathrm{COD}_{\mathrm{DEF}} ; 135^{\circ}-\mathrm{COD}$ and $\left.135^{\circ}-\mathrm{COD}_{\mathrm{DEF}}\right)$. These results are in line with previous findings obtained by Nimphius et al. [2]. The authors revealed a large statistically significant relationship between the COD deficit and COD test time (505 test). Furthermore, there was a large statistically significant relationship between COD deficits between angles $\left(90^{\circ}-\mathrm{COD}_{\mathrm{DEF}} \mathrm{vs} .135^{\circ}-\mathrm{COD}_{\mathrm{DEF}}\right)$, while it was not the case for $\mathrm{COD}$ test $\left(90^{\circ}\right.$-COD vs. $\left.135^{\circ}-\mathrm{COD}\right)$. The rationale for that results may be similar mechanical requirement between COD angles suggested by the Falch et al. [12] and Bourgeuis et al. [13], that angles below $90^{\circ}$ are more velocity-oriented, while angles above $90^{\circ}$ are more force-oriented. These data provides further support for the use of a COD deficit to evaluate an athlete's COD ability, as it removes the influence of linear running speed on such tests. Therefore, it seems that the obtained relationship between the COD deficits indicates that this measure provides information about the athlete's COD ability regardless of the angle, at least for $90^{\circ}$ - and $135^{\circ}$-COD. Thus, the COD deficits measure provides valuable information for the coaches, which allows the preparation of an individualized training program, e.g., whether the athletes require a complementary program aimed at improving the COD ability.

The present study has some limitations which must be addressed. The first limitation of the study is the assessment of relationships based only on a single value of external load during a squat exercise $(50 \% 1 \mathrm{RM})$. Hence, the results of the presented study do not translate to other loads. Moreover, only a single running length $(20 \mathrm{~m})$ for linear sprint and COD tests was examined, as well as the same number of direction changes ( 3 turns). In addition, these running tests were performed during one experimental session, so the impact of fatigue on the result cannot be ruled out. Taking into consideration the nature of soccer, relationships between high-intensity actions and angles below $90^{\circ}$ during COD should be analyzed, however sharper angles should not be completely ignored. Thus, future studies should provide a detailed relationship between different exercises (e.g., hip thrust) at a wide range of external loads and COD performance with variety of angles and numbers of direction change, in a large number of soccer players.

\section{Conclusions}

The results of the present study showed that 20-m linear sprinting speed, 1RM squat strength, power output obtained during squat at 50\% $1 \mathrm{RM}$ and COD ability at $90^{\circ}$ and $135^{\circ}$ angles, are separate physical qualities. Moreover, it seems that COD deficit provides a more isolated measure of COD ability than the COD tests alone and does not must be limited to a specific angle, but provides knowledge about the COD ability in a range of other angles, at least concerning $90^{\circ}$ and $135^{\circ} \mathrm{COD}$ angles. Thus, 
the lower the deficit time in athletes, the more effective the COD or the higher the ability of an athlete to COD relative to their physical ability for linear speed. What indicates that COD deficits provides an isolated measure of athletes' COD ability and is not biased towards superior lower-body peak power output or 1RM squat strength level and 20-m linear sprint. Therefore, practitioners are recommended to evaluate COD performance based on COD deficits to detect the athlete's capacity to change direction.

\section{Practical Applications}

The findings from this study show that COD deficit is an easy way to evaluate the COD ability in athletes. Therefore, coaches should use the COD deficit to enable the prescription of more targeted and individualized training programs to enhance the athletes' capability to perform directional changes. Based on this, coaches can implement a more comprehensive training strategy depending on whether the athlete would benefit more from developing the ability to change direction or from improving linear sprint performance.

Author Contributions: Conceptualization, M.P. and A.G.; data curation, M.O. and G.W.; formal analysis, R.R.; investigation, M.P. and M.O.; methodology, M.P. and A.G.; supervision, M.K. and A.G.; writing—original draft, M.K. and M.P.; writing-review \& editing, M.K. All authors have read and agree the published version of the manuscript.

Funding: The study was supported and funded by the statutory research of the Jerzy Kukuczka Academy of Physical Education in Katowice, Poland.

Conflicts of Interest: The authors declare that they have no conflicts of interest.

\section{References}

1. Lockie, R.G.; Murphy, A.J.; Spinks, C.D. Effects of resisted sled towing on sprint kinematics in field-sport athletes. J. Strength Cond. Res. 2003, 17, 760-767. [CrossRef]

2. Nimphius, S.; Callaghan, S.J.; Spiteri, T.; Lockie, R.G. Change of Direction Deficit: A More Isolated Measure of Change of Direction Performance Than Total 505 Time. J. Strength Cond. Res. 2016, 30, 3024-3032. [CrossRef]

3. Bloomfield, J.; Polman, R.; O'Donoghue, P. Physical Demands of Different Positions in FA Premier League Soccer. J. Sports Sci. Med. 2007, 6, 63-70.

4. Duthie, G.; Pyne, D.; Hooper, S. Time motion analysis of 2001 and 2002 super 12 rugby. J. Sports Sci. 2005, 23, 523-530. [CrossRef]

5. Vescovi, J.D.; Mcguigan, M.R. Relationships between sprinting, agility, and jump ability in female athletes. J. Sports Sci. 2008, 26, 97-107. [CrossRef]

6. Buchheit, M. Repeated-Sprint Performance in Team Sport Players: Associations with Measures of Aerobic Fitness, Metabolic Control and Locomotor Function. Int. J. Sports Med. 2012, 33, 230-239. [CrossRef]

7. Condello, G.; Minganti, C.; Lupo, C.; Benvenuti, C.; Pacini, D.; Tessitore, A. Evaluation of Change-of-Direction Movements in Young Rugby Players. Int. J. Sports Physiol. Perform. 2013, 8, 52-56. [CrossRef] [PubMed]

8. Sayers, M.G.L. Influence of Test Distance on Change of Direction Speed Test Results. J. Strength Cond. Res. 2015, 29, 2412-2416. [CrossRef] [PubMed]

9. Loturco, I.; Pereira, L.A.; Moraes, J.E.; Kitamura, K.; Cal Abad, C.C.; Kobal, R.; Nakamura, F.Y. Jump-Squat and Half-Squat Exercises: Selective Influences on Speed-Power Performance of Elite Rugby Sevens Players. PLoS ONE 2017, 12, e0170627. [CrossRef]

10. Suarez-Arrones, L.; Gonzalo-Skok, O.; Carrasquilla, I.; Asián-Clemente, J.; Santalla, A.; Lara-Lopez, P.; Núñez, F.J. Relationships between Change of Direction, Sprint, Jump, and Squat Power Performance. Sports 2020, 8, 38. [CrossRef] [PubMed]

11. Buchheit, M.; Haydar, B.; Ahmaidi, S. Repeated sprints with directional changes: Do angles matter? J. Sports Sci. 2012, 30, 555-562. [CrossRef] [PubMed]

12. Nygaard Falch, H.; Guldteig Rædergård, H.; van den Tillaar, R. Effect of Different Physical Training Forms on Change of Direction Ability: A Systematic Review and Meta-analysis. Sports Med. Open 2019, 5, 53. [CrossRef] [PubMed]

13. Bourgeuis, F.; McGuigan, M.R.; Gill, N.D.; Gamble, P. Physical characteristics and performance in change of direction tasks: A brief review and training considerations. J. Aust. Strength Cond. 2017, 25, 104-117. 
14. Nimphius, S.; Callaghan, S.J.; Bezodis, N.E.; Lockie, R.G. Change of Direction and Agility Tests: Challenging Our Current Measures of Performance. Strength Cond. J. 2018, 40, 26-38. [CrossRef]

15. Loturco, I.; Nimphius, S.; Kobal, R.; Bottino, A.; Zanetti, V.; Pereira, L.A.; Jeffreys, I. Change-of direction deficit in elite young soccer players: The limited relationship between conventional speed and power measures and change-of-direction performance. Ger. J. Exerc. Sport Res. 2018, 48, 228-234. [CrossRef]

16. Cuthbert, M.; Thomas, C.; Dos'Santos, T.; Jones, P.A. Application of Change of Direction Deficit to Evaluate Cutting Ability. J. Strength Cond. Res. 2019, 33, 2138-2144. [CrossRef]

17. Siegel, J.A.; Gilders, R.M.; Staron, R.S.; Hagerman, F.C. Human muscle power output during upper- and lower-body exercises. J. Strength Cond. Res. 2002, 16, 173-178.

18. Wilk, M.; Golas, A.; Zmijewski, P.; Krzysztofik, M.; Filip, A.; Coso, J.D.; Tufano, J.J. The Effects of the Movement Tempo on the One-Repetition Maximum Bench Press Results. J. Hum. Kinet. 2020, 72, 151-159. [CrossRef]

19. Wilk, M.; Gepfert, M.; Krzysztofik, M.; Mostowik, A.; Filip, A.; Hajduk, G.; Zajac, A. Impact of Duration of Eccentric Movement in the One-Repetition Maximum Test Result in the Bench Press among Women. J. Sports Sci. Med. 2020, 19, 317-322.

20. Martínez-Cava, A.; Morán-Navarro, R.; Sánchez-Medina, L.; González-Badillo, J.J.; Pallarés, J.G. Velocityand power-load relationships in the half, parallel and full back squat. J. Sports Sci. 2019, 37, 1088-1096. [CrossRef]

21. Hopkins, W.G. Measures of Reliability in Sports Medicine and Science. Sports Med 2000, 30, 1-15. [CrossRef] [PubMed]

22. Wisloff, U. Strong correlation of maximal squat strength with sprint performance and vertical jump height in elite soccer players. Br. J. Sports Med. 2004, 38, 285-288. [CrossRef] [PubMed]

23. Yetter, M.; Moir, G.L. The Acute Effects of Heavy Back and Front Squats on Speed during Forty-Meter Sprint Trials. J. Strength Cond. Res. 2008, 22, 159-165. [CrossRef] [PubMed]

24. Contreras, B.; Vigotsky, A.D.; Schoenfeld, B.J.; Beardsley, C.; McMaster, D.T.; Reyneke, J.H.T.; Cronin, J.B. Effects of a Six-Week Hip Thrust vs. Front Squat Resistance Training Program on Performance in Adolescent Males: A Randomized Controlled Trial. J. Strength Cond. Res. 2017, 31, 999-1008. [CrossRef]

25. González-García, J.; Morencos, E.; Balsalobre-Fernández, C.; Cuéllar-Rayo, Á.; Romero-Moraleda, B. Effects of 7-Week Hip Thrust Versus Back Squat Resistance Training on Performance in Adolescent Female Soccer Players. Sports 2019, 7, 80. [CrossRef] [PubMed]

26. López-Segovia, M.; Marques, M.; van den Tillaar, R.; González-Badillo, J. Relationships Between Vertical Jump and Full Squat Power Outputs With Sprint Times in U21 Soccer Players. J. Hum. Kinet. 2011, 30, 135-144. [CrossRef]

27. Rouissi, M.; Chtara, M.; Owen, A.; Chaalali, A.; Chaouachi, A.; Gabbett, T.; Chamari, K. Effect of leg dominance on change of direction ability amongst young elite soccer players. J. Sports Sci. 2016, 34, 542-548. [CrossRef]

28. Loturco, I.; Pereira, L.A.; Reis, V.P.; Abad, C.C.C.; Freitas, T.T.; Azevedo, P.H.S.M.; Nimphius, S. Change of Direction Performance in Elite Players From Different Team Sports. J. Strength Cond. Res. 2020, 1. [CrossRef]

(C) 2020 by the authors. Licensee MDPI, Basel, Switzerland. This article is an open access article distributed under the terms and conditions of the Creative Commons Attribution (CC BY) license (http://creativecommons.org/licenses/by/4.0/). 